\title{
Management of appendiceal pseudomyxoma peritonei diagnosed during pregnancy Erika Haase $^{1}$, Dal Yoo² and Paul H Sugarbaker*2
}

\author{
Address: ${ }^{1}$ Department of Surgical Oncology, Princess Margaret Hospital, University of Toronto, Toronto, Ontario, Canada and ${ }^{2}$ Program in \\ Peritoneal Surface Malignancy, Washington Cancer Institute, Washington Hospital Center, Washington, District of Columbia, USA \\ Email: Erika Haase - erikahaase@shaw.ca; Dal Yoo - dalyoo@aol.com; Paul H Sugarbaker* - Paul.Sugarbaker@medstar.net \\ * Corresponding author
}

Published: 19 May 2009

World Journal of Surgical Oncology 2009, 7:48 doi:10.1 186/1477-78/9-7-48

This article is available from: http://www.wjso.com/content/7/1/48

(C) 2009 Haase et al; licensee BioMed Central Ltd.

This is an Open Access article distributed under the terms of the Creative Commons Attribution License (http://creativecommons.org/licenses/by/2.0), which permits unrestricted use, distribution, and reproduction in any medium, provided the original work is properly cited.

\begin{abstract}
Background: The incidence of cancer during pregnancy is approximately I in 1000. The most common types encountered during pregnancy are cervical, breast and ovarian. Epithelial tumors of the appendix on the other hand are rare and account for only approximately $1 \%$ of all colorectal neoplasms; the occurrence of this neoplasm during pregnancy is extremely rare.
\end{abstract}

Case Presentation: The medical history of a 30 year old woman diagnosed at 17 weeks gestation with an appendiceal mucinous tumor with large volume pseudomyxoma peritonei was presented. Her pregnancy was preserved and she had an early vaginal delivery of a healthy baby at 35 weeks. At 2 I/2 weeks postpartum the patient underwent extensive cytoreductive surgery and intraperitoneal chemotherapy. She remains disease-free 5 years after her initial diagnosis. A literature review of this clinical situation and a discussion of treatment plans were presented.

Conclusion: The management of an appendiceal tumor with pseudomyxoma peritonei diagnosed during pregnancy requires full knowledge of the natural history of this disease to achieve a balance of concern for maternal survival and fetal health.

\section{Background}

Epithelial tumors of the appendix are rare, accounting for approximately $1 \%$ of all colorectal neoplasms [1]. The tumor can range in presentation from a malignant mucocele found at routine appendectomy, to a ruptured high grade appendiceal malignancy with large volume pseudomyxoma peritonei [2]. During pregnancy, cancer occurs in approximately 1 in 1000 women, with the most common types being cervical, breast and ovarian [3]. There are only a few reports of appendiceal tumors occurring during pregnancy. Management of malignancy during pregnancy is challenging, requiring a balance of concern for maternal survival and fetal health and wellbeing. The management plan, which may require induced abortion, is determined by the stage of pregnancy and the predicted behavior of the cancer. We present here the medical history of a patient having an appendiceal mucinous tumor with large volume pseudomyxoma peritonei syndrome during pregnancy and the treatments she had at our institution. A review of the literature regarding this clinical situation and a discussion of treatment options are presented.

\section{Case presentation}

A 30 year old primagravid woman at 17 weeks gestation was found on routine prenatal ultrasound to have a complex right ovarian mass. She underwent surgery and was found to have a ruptured appendiceal mucinous neo- 
plasm with a large volume pseudomyxoma peritonei syndrome. The right ovary and appendix were removed and an omental biopsy was performed. The final pathology confirmed a well-differentiated mucinous adenocarcinoma of appendiceal origin. She recovered without incident from this surgery and was referred for assessment to the Washington Hospital Center at 26 weeks gestation. In consultation with the patient and her obstetrician it was decided to preserve the pregnancy and schedule an early vaginal delivery at 35 weeks gestation.

Following an uncomplicated vaginal delivery of a healthy baby, she underwent a staging CT. It showed no evidence of metastases within the liver parenchyma or outside of the peritoneal cavity. A large volume of mucinous cancer was imaged beneath right and left hemidiaphragm and in the pelvis. Small bowel except for the terminal ileum was spared. Preoperative tumor markers revealed an elevated CEA at $68.2 \mathrm{ng} / \mathrm{mL}$ (normal 0-5 ng/mL), CA-125 of 177 units/mL (normal 0-35 units/mL) and CA 19-9 of 361 units/mL (normal 0-37 units/mL).

At 2 1/2 weeks after delivery, the patient underwent an abdominal exploration followed by cytoreductive surgery. She had thick, densely packed tumor covering most of the parietal peritoneal surface, with an especially large volume of disease in the lesser omentum, omental bursa and surrounding the porta hepatis. The stomach and the small bowel except for the terminal ileum were spared. An extensive cytoreduction surgery was performed including total anterior parietal peritonectomy and resection of tumor in the abdominal wall scar, greater and lesser omentectomy with stripping of the omental bursa, right and left upper quadrant peritonectomies including total diaphragm stripping bilaterally, splenectomy, electroevaporation of tumor on liver capsule, cholecystectomy, and a right hemicolectomy including the distal $15 \mathrm{~cm}$ of terminal ileum. A total pelvic peritonectomy with abdominal hysterectomy, left salpingo-oophorectomy and rectosigmoid colon resection was performed. The peritoneal cancer index score was 28 (out of a maximum of 39), and the cytoreduction was scored as complete (residual tumor less than $2.5 \mathrm{~mm}$ ) [4]. Intraoperative intraperitoneal heated chemotherapy was administered through the open coliseum technique, with $15 \mathrm{mg} / \mathrm{m}^{2}$ mitomycin $\mathrm{C}$ at $41.5^{\circ} \mathrm{C}$ for 90 minutes. A Tenckhoff catheter and JacksonPratt drains were inserted for early postoperative intraperitoneal 5-fluorouracil chemotherapy [5]. Following completion of the hyperthermic intraoperative intraperitoneal chemotherapy an ileocolic and colorectal anastomosis was performed. The total operating time was 9 hours, and the blood loss was estimated at $350 \mathrm{~mL}$, with 2 units of packed red blood cells and 4 units of fresh frozen plasma administered during the operation.
On postoperative day 1 through 5, $900 \mathrm{mg}$ intraperitoneal 5 -fluorouracil in $1.5 \%$ dextrose peritoneal dialysis solution was administered daily for 23 hours. The patient developed uncomplicated neutropenia on postoperative day 16 , with neutrophil count of $0.9 \times 10^{3} / \mathrm{uL}$ and a total leukocyte count of $1.3 \times 10^{3} / \mathrm{uL}$, which was treated successfully with granulocyte colony stimulating factor. On postoperative day 18 she was diagnosed with a left lower extremity deep venous thrombosis and was treated with intravenous heparin which was converted to warfarin prior to discharge from the hospital. She had a postoperative ileus requiring nasogastric drainage for 2 weeks and received total parenteral nutrition during this time. She was discharged in good condition on postoperative day 24.

Three weeks following surgery her tumor marker levels decreased with CEA at $0.5 \mathrm{ng} / \mathrm{mL}$, CA 125 at 92.1 units/ $\mathrm{mL}$, and CA $19-9$ at 10.6 units/mL. CA 125 normalized by 2 months post-operatively.

After recovery from surgery, she was treated with the Xelox regimen (Xeloda $1000 \mathrm{mg} / \mathrm{m}^{2}$ bid for 14 days then 7 day rest and oxaliplatin $130 \mathrm{mg} / \mathrm{m}^{2}$ intravenous over $90 \mathrm{~min}$ utes on day 1) for 8 cycles over 24 weeks.

In follow-up at five years after, the patient and her child are in good condition. She has had two episodes of transient small bowel obstruction treated conservatively. On her most recent clinical, radiologic and biochemical assessment at 5 years after her initial diagnosis she remains disease-free.

\section{Discussion}

Pseudomyxoma peritonei syndrome is a rare disease registered as number 843 by the National Organization for Rare Disorders [6]. To our knowledge there is only one previous report of a disseminated appendiceal tumor occurring during pregnancy [7]. Our case of pseudomyxoma peritonei presenting in early pregnancy highlights some interesting challenges in the management of cancer in pregnancy. In this case, as in most other cancers occurring during pregnancy, there is a paucity of evidence to guide the clinician in optimal management. Maternal health and timely treatment of the malignancy is balanced by health and safety of the fetus, as many treatment interventions, including abdominal surgery, radiation, and chemotherapy, are known to be harmful to the fetus. Therefore during pregnancy, in addition to the stage and prognosis of the cancer, the stage and value of the pregnancy must also be considered.

For cancer diagnosed during the latter part of pregnancy, an optimal decision often involves a negligible delay in definitive treatment following an early delivery at about 
34 weeks gestation when the risk to the premature infant is quite low. During the first trimester the fetus is most susceptible to teratogenic effects; $\mathrm{x}$-rays and most chemotherapeutic agents are contraindicated. Also, spontaneous abortion is common. A long delay in treatment of an aggressive cancer is often unacceptable to the woman and her treating physicians, and a recommendation for termination of the pregnancy must be considered. During the second trimester, as in our patient, abdominal surgical procedures have the lowest risk of spontaneous abortion or premature labor. Additionally, many chemotherapeutic agents have been successfully used in the second and third trimester. Plain radiographs and even abdominal CT scans pose minimal risk to the fetus at this stage of the pregnancy. With increasing experience with abdominal MRI, this is becoming the recommended imaging modality for pregnant women with appendiceal or other gastrointestinal malignancy.

In our patient the appropriate diagnostic surgical evaluation, an appendectomy, was made at the safest time, during the second trimester. Unexpectedly at laparotomy, a diagnosis of large volume pseudomyxoma peritonei from a ruptured appendiceal mucinous carcinoma was made. The natural history of pseudomyxoma peritonei was then considered to guide our management [8]. As described by Ronnett and coworkers pseudomyxoma peritonei describes mucinous intraabdominal tumors usually of appendiceal origin with a broad spectrum of aggressiveness. The low grade appendiceal mucinous tumors (disseminated peritoneal adenomucinosis) usually have a slowly progressive course over several years. The clinical entity with the non-invasive disease is referred to as pseudomyxoma peritonei syndrome. In contrast mucinous carcinomatosis from poorly differentiated cancers of the appendix usually with signet ring morphology have an aggressive behavior, progress rapidly, and carry a worse prognosis. Well-differentiated appendiceal mucinous adenocarcinoma with pseudomyxoma peritonei, as in our patient, is a less aggressive disease, shows a less rapid progression and an intermediate prognosis.

With all appendiceal mucinous neoplasms the prognosis is dependent not only on the histologic grade of the tumor but also the completeness of cytoreduction score [9]. The volume of intraabdominal tumor as assessed by the peritoneal cancer index has no impact on prognosis $[9,10]$. In this patient a delay in definitive treatment undoubtedly allowed an increase in tumor volume to occur. However, since the cytoreduction was complete, minimal compromise in the prognosis was expected.

In a review of the literature, there have been 7 previous reports of appendiceal mucinous tumors occurring during pregnancy in the absence of pseudomyxoma peritonei syndrome [7,11-16]. Six were appendiceal mucinous tumors confined to the appendix and one non-mucinous appendiceal adenocarcinoma with peritoneal carcinomatosis (Table 1). In one case, the diagnosis was made in the third trimester and an early delivery was carried out prior to definitive treatment. In one case the diagnosis was made at the time of Cesarean section at term. Four patients presented with an acute abdomen and the diagnosis of appendicitis, with the correct diagnosis being revealed at laparotomy. One of these patients elected to have a therapeutic abortion prior to reoperation for a right hemicolectomy, one patient had a right hemicolectomy at initial operation at 26 weeks gestational age and went on to deliver at term, and the remaining two were treated with appendectomy. The final patient was diagnosed in very early pregnancy at the time of a spontaneous abortion, and underwent surgical treatment 3 months later after progression of disease was revealed on imaging.

Based on our case and the previous case reports, it appears reasonable to carry out a diagnostic surgical evaluation of a mucinous appendiceal tumor during pregnancy, ideally in the second or third trimester. If a patient presents with an acute abdomen from a ruptured mucinous tumor, initial surgery should consist of a complete appendectomy and mesoappendectomy, and biopsy of omental or peritoneal tumor deposits. Since the rate of lymph node positivity in appendiceal mucinous neoplasms is less than $5 \%$, more extensive surgery involving a right hemicolectomy at the time of initial diagnosis is not warranted and poses undue risk to the mother and fetus [17]. Definitive management of moderate or low grade appendiceal cancer with pseudomyxoma peritonei should be delayed until after delivery, as extensive cytoreduction and intraperitoneal chemotherapy would be impossible and contraindicated during pregnancy. It is reasonable to have the delivery at an earlier date, 34-35 weeks gestation, in order not to further delay treatment of appendiceal adenocarcinoma (Table 2). The method for childbirth is important if the delivery is to occur prior to definitive cytoreduction. A vaginal delivery is required. A Cesarean section is contraindicated. An abdominal incision for Cesarean section will allow for mucinous cancer cells to implant and progress within the abdominal incision and parametrial tissues. This would potentially compromise the completeness of cytoreduction and the likelihood of a curative result [18]. If a Caesarian section is necessary for obstetrical reasons, a midline incision should be used, which can be excised with subsequent cytoreductive surgery. Stage for stage, one would postulate that pregnant cancer patients with pseudomyxoma peritonei may have similar outcomes as non-pregnant patients. With optimal management including complete cytoreduction and intraperitoneal chemotherapy, patients with pseudomyxoma 
Table I: Case reports of appendiceal epithelial (mucinous) tumors during pregnancy.

\begin{tabular}{|c|c|c|c|c|c|c|c|}
\hline $\begin{array}{l}\text { Haase } \\
\text { (current case) }\end{array}$ & $\begin{array}{l}\text { Well-differentiated } \\
\text { mucinous } \\
\text { adenocarcinoma with } \\
\text { pseudomyxoma } \\
\text { peritonei syndrome }\end{array}$ & 17 weeks & $\begin{array}{l}\text { Incidental finding on } \\
\text { routine prenatal } \\
\text { ultrasound }\end{array}$ & $\begin{array}{l}\text { Laparotomy, right } \\
\text { salpingo- } \\
\text { oophorectomy, } \\
\text { appendectomy, } \\
\text { omental biopsy }\end{array}$ & $\begin{array}{l}\text { Complete } \\
\text { cytoreductive surgery } \\
\text { with HIPEC and EPIC } \\
\text { after delivery, and } \\
\text { adjuvant chemotherapy }\end{array}$ & $\begin{array}{l}\text { Early induction and } \\
\text { vaginal delivery of } \\
\text { healthy baby at } 35 \\
\text { weeks }\end{array}$ & 5 years, no recurrence \\
\hline
\end{tabular}

\begin{tabular}{|c|c|c|c|c|c|c|c|}
\hline $\begin{array}{l}\text { Sebire } \\
2000[7]\end{array}$ & $\begin{array}{l}\text { Moderately- } \\
\text { differentiated } \\
\text { appendiceal } \\
\text { adenocarcinoma with } \\
\text { peritoneal } \\
\text { carcinomatosis and } \\
\text { liver metastases }\end{array}$ & 29 weeks & $\begin{array}{l}\text { Lower abdominal pain } \\
\text { and vomiting }\end{array}$ & $\begin{array}{l}\text { Diagnostic workup of } \\
\text { metastatic disease } \\
\text { (liver biopsy) }\end{array}$ & $\begin{array}{l}\text { Palliative debulking } \\
\text { (omentectomy, } \\
\text { appendectomy, left } \\
\text { oophorectomy) at time } \\
\text { of Cesarean section. } \\
\text { Adjuvant 5-FU, } \\
\text { epirubicin and } \\
\text { carboplatin }\end{array}$ & $\begin{array}{l}\text { Cesarean section at } 30 \\
\text { weeks, healthy baby }\end{array}$ & $\begin{array}{l}6 \text { months post } \\
\text { treatment clinically well } \\
\text { but residual tumor in } \\
\text { right iliac fossa and liver }\end{array}$ \\
\hline
\end{tabular}

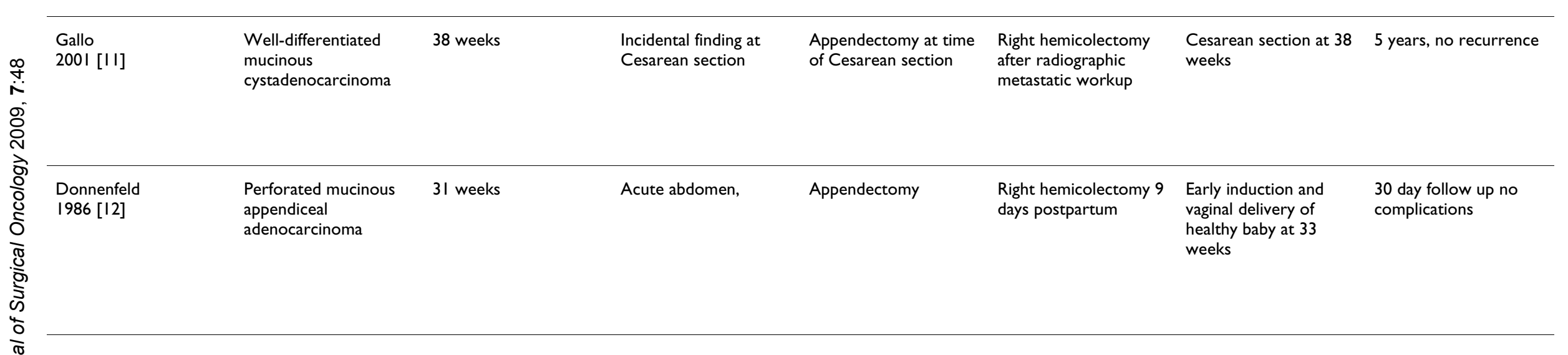


Table I: Case reports of appendiceal epithelial (mucinous) tumors during pregnancy. (Continued)

\begin{tabular}{|c|c|c|c|c|c|c|c|}
\hline $\begin{array}{l}\text { Morgan } \\
2004[13]\end{array}$ & $\begin{array}{l}\text { Well-differentiated } \\
\text { mucinous } \\
\text { adenocarcinoma, } \\
\text { negative peritoneal } \\
\text { washings }\end{array}$ & 26 weeks & Acute abdomen & Right hemicolectomy & No further treatment & $\begin{array}{l}\text { Vaginal delivery of } \\
\text { healthy baby at term }\end{array}$ & $\begin{array}{l}36 \text { months, no } \\
\text { recurrence }\end{array}$ \\
\hline $\begin{array}{l}\text { Zeteroglu } \\
2003[14]\end{array}$ & $\begin{array}{l}\text { Mucinous appendiceal } \\
\text { cystadenocarcinoma }\end{array}$ & 21 weeks & Acute abdomen & Appendectomy & $\begin{array}{l}\text { Right hemicolectomy, } \\
\text { omentectomy }\end{array}$ & $\begin{array}{l}\text { Terminated at } 21 \\
\text { weeks }\end{array}$ & I year, no recurrence \\
\hline $\begin{array}{l}\text { Casey } \\
2003[15]\end{array}$ & $\begin{array}{l}\text { Perforated mucinous } \\
\text { cystadenoma }\end{array}$ & 21 weeks & Acute abdomen & Appendectomy & No further treatment & miscarriage & $\begin{array}{l}\text { Discharged well } 4 \text { days } \\
\text { after surgery }\end{array}$ \\
\hline $\begin{array}{l}\text { Kalu } \\
2005[16]\end{array}$ & $\begin{array}{l}\text { Mucinous adenoma } \\
\text { with mucocele }\end{array}$ & 5 weeks & $\begin{array}{l}\text { Incidental ultrasound } \\
\text { finding at time of } \\
\text { vaginal bleeding }\end{array}$ & $\begin{array}{l}\text { Observation with serial } \\
\text { imaging (follow-up } \\
\text { ultrasound } 3 \text { months) }\end{array}$ & $\begin{array}{l}\text { Appendectomy } 3 \\
\text { months later when } \\
\text { mass doubled in size }\end{array}$ & $\begin{array}{l}\text { Spontaneous abortion } \\
\text { at } 6 \text { weeks }\end{array}$ & $\begin{array}{l}\text { Discharged well } 4 \text { days } \\
\text { after surgery }\end{array}$ \\
\hline
\end{tabular}

HIPEC: heated intraperitoneal chemotherapy

EPIC: early postoperative intraperitoneal chemotherapy

5-FU: 5-fluorouracil

$\stackrel{\infty}{+\infty}$

क् Table 2: Suggested management strategy for pseudomyxoma peritonei syndrome occurring during pregnancy.

글 Mgressive Malignancy

\begin{tabular}{|c|c|c|c|c|}
\hline Week of Pregnancy & Diagnostic Tests & CRS + HIPEC & Diagnostic Tests & CRS + HIPEC \\
\hline $0-12$ & Unsafe & Consider pregnancy termination & Unsafe & Delay treatment to 35 weeks \\
\hline $13-27$ & Safe & Consider pregnancy termination & Safe & Delay treatment to 35 weeks \\
\hline $28-40$ & Safe & Delay treatment to 35 weeks & Safe & Delay treatment to term \\
\hline
\end{tabular}


peritonei from well-differentiated appendiceal mucinous carcinoma will have a 15-year survival of 50\% [9].

Koops and colleagues wrote about pseudomyxoma peritonei syndrome diagnosed in women who were attempting pregnancy (Koops A, Smeenk RM, Zoetmulder FAN, Hoek A. Pseudomyxoma peritonei and pregnancy. Report of two cases, unpublished data). They recommend that definitive treatment of the appendiceal tumor be delayed to allow pregnancy to occur if the disease was minimally aggressive. In patients with progressive disease their experience with delay led to an advanced, untreatable disease state.

\section{Conclusion}

In patients with slow or moderate advance of disease, the pregnancy (or pregnancy wish) should be allowed to proceed to a vaginal delivery. In patients with a rapid progression, termination of the pregnancy and definitive treatment may be necessary to protect the mother.

\section{Abbreviations}

CEA: carcinoembryonic antigen; CA 19-9: cancer antigen 19-9; CA 125: cancer antigen 125; CT: computed tomography.

\section{Consent}

Written informed consent was obtained from the patient for publication of this case report and any accompanying images. A copy of the written consent is available for review by the Editor-in-Chief of this journal.

\section{Competing interests}

The authors declare that they have no competing interests.

\section{Authors' contributions}

All Authors made substantial contributions to the concept, design, acquisition of data, analysis and interpretation of data, drafting and revising the intellectual content of the manuscript. All Authors read and approved the final manuscript.

\section{References}

I. Moran BJ, Cecil TD: The etiology, clinical presentation, and management of pseudomyxoma peritonei. Surg Oncol Clin N Am 2003, 12:585-603.

2. Sugarbaker PH: New standard of care for appendiceal epithelial neoplasms and pseudomyxoma peritonei syndrome? Lancet Oncol 2006, 7:69-76.

3. Donegan WL: Cancer and pregnancy. CA Cancer J Clin 1983 , 33:194-214

4. Jacquet $\mathrm{P}$, Sugarbaker $\mathrm{PH}$ : Current methodologies for clinical assessment of patients with peritoneal carcinomatosis. J Exp Clin Cancer Res 1996, I 5:49-58.

5. Sugarbaker PH: The Washington Cancer Institute experience in the management of carcinomatosis, peritoneal mesothelioma, and sarcomatosis. Curr Res in Cancer 2007, I: I 3-54.

6. Sugarbaker PH: Current concepts of the pseudomyxoma peritonei syndrome: A benign tumor, often a needless fatal outcome. J Rare Diseases 1997, 3:5-18.
7. Sebire NJ, Osborn M, Darzi A, Farthing A, Goldin RD: Appendiceal adenocarcinoma with ovarian metastases in the third trimester of pregnancy. J R Soc Med 2000, 93: I92-193.

8. Ronnett BM, Zahn CM, Kurman RJ, Kass ME, Sugarbaker PH Shmookler BM: Disseminated peritoneal adenomucinosis and peritoneal mucinous carcinomatosis: A clinicopathologic analysis of 109 cases with emphasis on distinguishing pathologic features, site of origin, prognosis, and relationship to "pseudomyxoma peritonei.". Am J Surg Pathol I995, 19:1390-1408.

9. Sugarbaker $\mathrm{PH}$, Chang D: Results of treatment of $\mathbf{3 8 5}$ patients with peritoneal surface spread of appendiceal malignancy. Ann Surg Oncol 1999, 6:727-731.

10. Sugarbaker PH, Jablonski KA: Prognostic features of 5 I colorectal and I 30 appendiceal cancer patients with peritoneal carcinomatosis treated by cytoreductive surgery and intraperitoneal chemotherapy. Ann Surg 1995, 22 I: | 24-। 32.

II. Gallo JL, Martinez-Ossa R, Ferrer G, Camara M: Mucinous appendiceal cystadenocarcinoma and pregnancy. Am J Perinatol $200 \mathrm{I}$, I 8:155-157.

12. Donnenfeld AE, Roberts NS, Losure TA, Mellen AW: Perforated adenocarcinoma of the appendix during pregnancy. $\mathrm{Am}$ Obstet Gynecol 1986, I 54:637-638.

13. Morgan DR, Fernandez CO, DeSarno C, Mann WJ Jr: Adenocarcinoma of the appendix in pregnancy: a case report. J Reprod Med 2004, 49:753-755.

14. Zeteroglu S, Kotan C, Ozen S, Goktolga U: Mucinous appendicular cystadenocarcinoma during pregnancy. A case report. J Reprod Med 2003, 48:83I-833.

15. Casey RG, Tan M, Salman R, Ryan J, Gillen P: Acute abdomen in pregnancy due to mucinous cystadenoma of the appendix. Obstet Gynaecol 2003, 23:566-567.

16. Kalu E, Croucher C: Appendiceal mucocele: a rare differential diagnosis of a cystic right adnexal mass. Arch Gynecol Obstet 2005, 27 I:86-88.

17. Gonzalez-Moreno S, Sugarbaker PH: Right hemicolectomy does not confer a survival advantage in patients with mucinous carcinoma of the appendix and peritoneal seeding. $\mathrm{Br} J \mathrm{Surg}$ 2004, 91 :304-3II.

18. Sugarbaker PH: Peritoneum as the first-line of defense in carcinomatosis. J Surg Oncol 2007, 95:93-96.

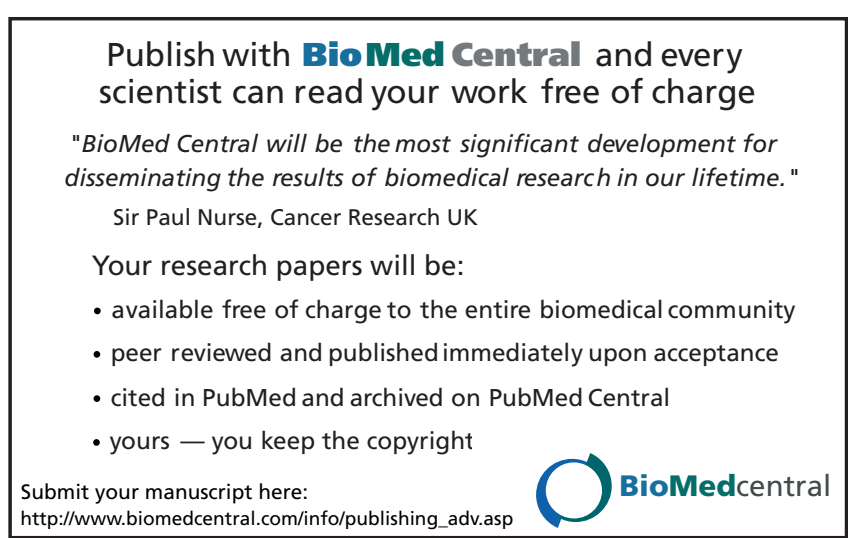

